\title{
A case report of fractured guidewire removal by rotational atherectomy
}

\author{
Xu Wang (®), Jian Ye, Jun-Qing Gao and Zong-Jun Liu*
}

\begin{abstract}
Background: Fractures occur in association with manipulation and because of the complexity of the coronary artery, and they can cause a series of serious complications, such as myocardial infarction and secondary thrombosis. Common treatments for fractured guidewires include conservative, interventional and surgical methods.

Case presentations: A 67-year-old male was admitted to our institute. He had recurrent chest tightness and chest pain for half a month, which worsened in one day. He was diagnosed with acute non-ST-segment elevation myocardial infarction. Guidewire fracture was caused by improper manipulation during percutaneous coronary intervention. We successfully performed rotational atherectomy to remove the fractured guidewire. His symptoms, and condition improved 6 weeks after the removal of fractured guidewire.
\end{abstract}

Conclusion: Physicians should have higher requirements for the quality of the guidewires and operation techniques. Keywords: Rotational atherectomy, Percutaneous coronary intervention, Fractured guidewire, Drug-eluting stent

\section{Background}

Coronary stenting is a common and effective method for the treatment of coronary heart disease. Fractured guidewires are a rare complication of percutaneous coronary intervention. Fractures occur in association with manipulation and because of the complexity of the coronary artery, and they can cause a series of serious complications, such as myocardial infarction and secondary thrombosis. Common treatments for fractured guidewires include conservative, interventional and surgical methods. This article reports a case of guidewire fracture caused by improper manipulation during percutaneous coronary intervention. We successfully performed rotational atherectomy to remove the fractured guidewire.

*Correspondence: 95885209@qq.com

Department of Cardiology, Putuo Hospital, Shanghai University of Traditional Chinese Medicine, Shanghai 200062, People's Republic of China

\section{Case presentation}

A 67-year-old male was admitted to our institute on May 31,2020 . He had recurrent chest tightness and chest pain for half a month, which worsened in one day. Vital Signs were:blood pressure $124 / 80 \mathrm{mmHg}$, pulse 75 / min,respirations $22 / \mathrm{min}$. Electrocardiogram exhibited ST-segment elevation in some leads, Myocardial enzyme profiles were: myoglobin: $>1000 \mathrm{ng} / \mathrm{ml}$, brain natriuretic peptide: $66.88 \mathrm{pg} / \mathrm{ml}$, kinase isoenzyme: $127.58 \mathrm{ng} / \mathrm{ml}$, hypersensitive troponin I: $102.358 \mathrm{ng} / \mathrm{ml}$. He was diagnosed with acute non-ST-segment elevation myocardial infarction. Diagnostic angiography showed that the LCX had 100\% stenosis. The LAD had severe stenosis in the proximal and middle portions. The RCA had severe stenosis in the middle portion. Therefore, we directly implanted a $3.0 * 28$ rapamycin-eluting stent in the distal part of the LCX. Dilatation pressure was $11 \mathrm{ATM}^{*} 10 \mathrm{~s}$. Then, we planned to implant another stent. Unfortunately, the stent failed to cross the lesion. We tried to use a Guidezilla catheter to insert a stent. However, the stent still had not passed through the lesion. Then, we decided to insert a double guidewire. When the guidewire passed original author(s) and the source, provide a link to the Creative Commons licence, and indicate if changes were made. The images or other third party material in this article are included in the article's Creative Commons licence, unless indicated otherwise in a credit line to the material. If material is not included in the article's Creative Commons licence and your intended use is not permitted by statutory regulation or exceeds the permitted use, you will need to obtain permission directly from the copyright holder. To view a copy of this licence, visit http://creativecommons.org/licenses/by/4.0/. The Creative Commons Public Domain Dedication waiver (http://creativeco mmons.org/publicdomain/zero/1.0/) applies to the data made available in this article, unless otherwise stated in a credit line to the data. 
through the distal end of the stent, it inserted into the stent and hooked on its edge. The guidewire was not successfully withdrawn and broke. IVUS showed that the broken end of the guidewire was $40 \mathrm{~mm}$ inside the guiding catheter (Fig. 1). We decided to insert a rotational catheter to cut the guidewire in the LCX so that we could remove the guidewire. Therefore, we implanted a $1.5 \mathrm{~mm}$ rotational catheter at $144,000 \mathrm{rpm} * 18 \mathrm{~s}$. Angiography indicated that the guidewire was successfully divided into two parts. One part was in the guiding catheter (which is usually in the main coronary artery), and the other part was in the LCX (Fig. 2). We used the balloon to squeeze the guidewire in the guiding catheter. Then, we removed the guidewire together with the guiding catheter. After that, we placed the catheter under IVUS guidance again to confirm the position of the broken end of the guidewire in the LCX (Fig. 3). We implanted a 3.5*20 rapamycin-eluting stent to link it with the original stent (Fig. 4). The expansion pressure was $8 \mathrm{ATM}^{*} 10 \mathrm{~s}$. The remaining guidewire was covered by the stent. In the end, the LCX had no stenosis. The treated coronary arteries had TIMI grade 3 blood flow, and there were no parts of
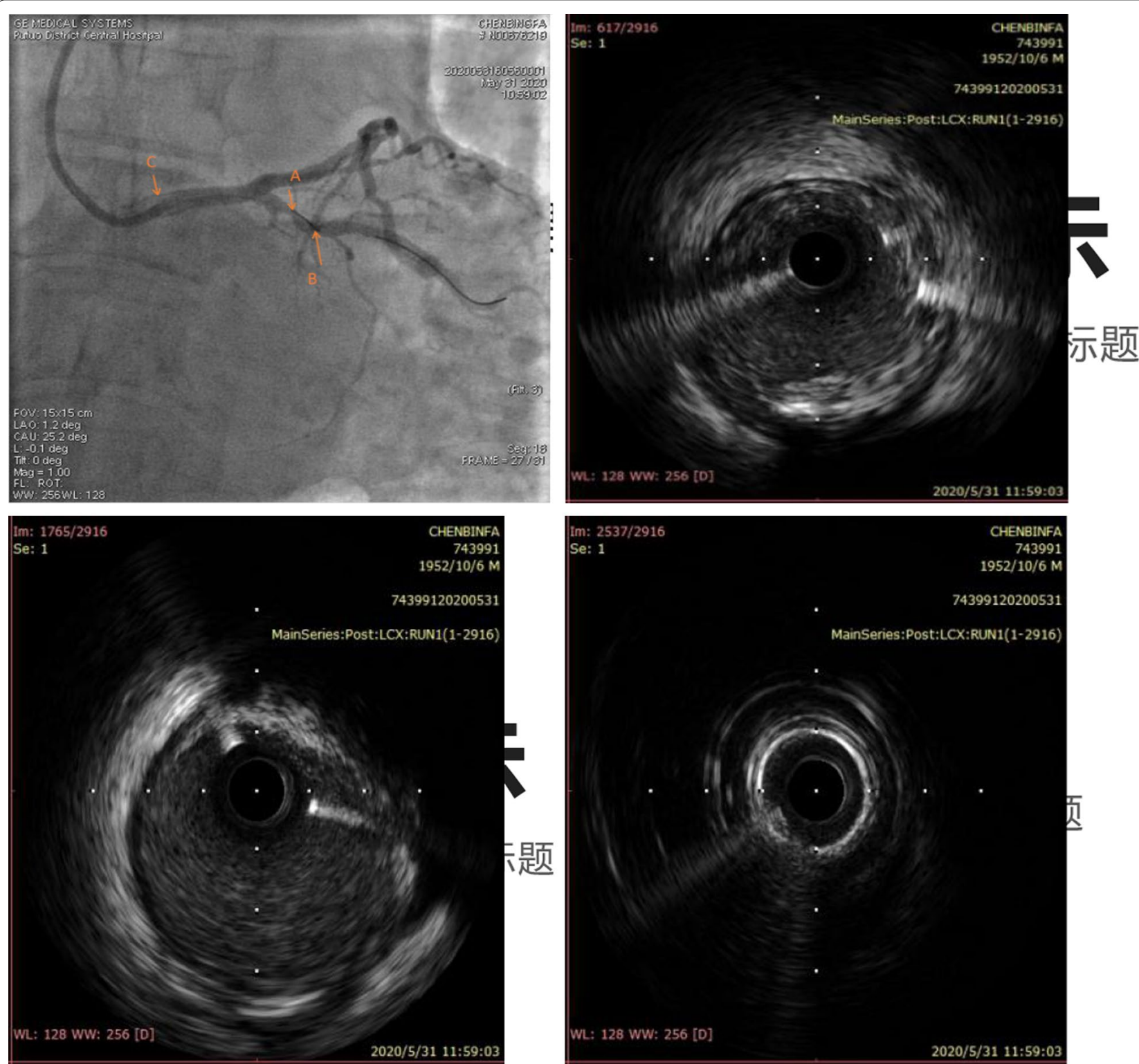

Fig. 1 Fractured guidewire in the LCX (A B C). A The proximal end of the broken guide wire. B The distal end of the broken guide wire. $\mathbf{C}$ Left main coronary artery opening 


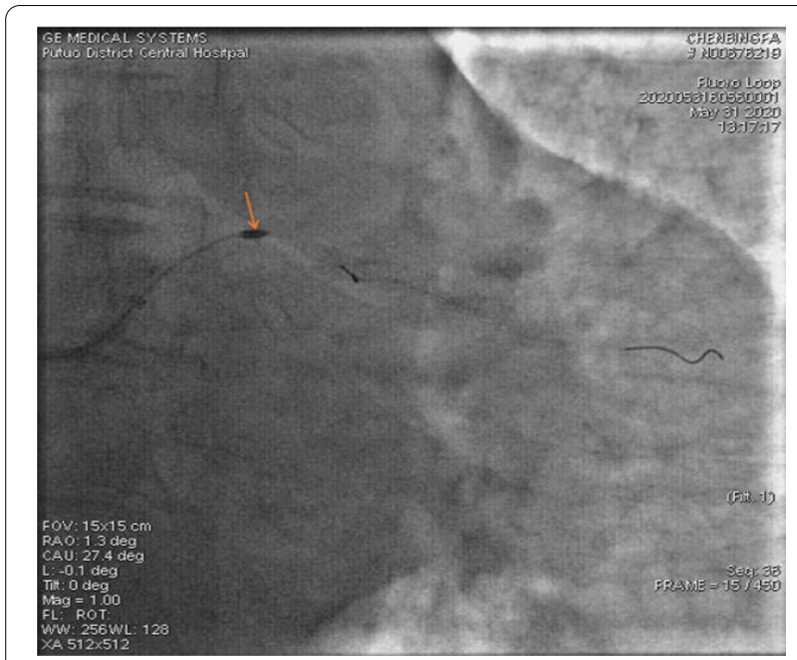

Fig. 2 Rotary-grinding guidewire

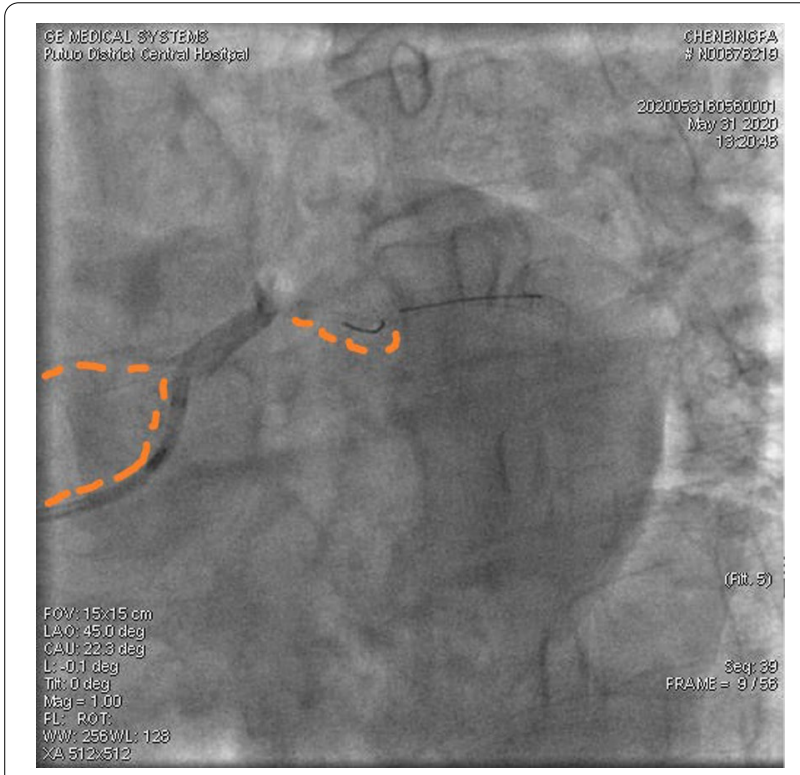

Fig. 3 Results of post coronary rotation

the guidewire in the stent (Fig. 5). He received aspirin $100 \mathrm{mg} /$ day and clopidogrel $75 \mathrm{mg} /$ day as double antiplatelet therapy after PCI.

Six months later, the patient was admitted to the hospital for re-examination. Coronary angiography indicated that there was no restenosis in the stent. IVUS showed that the stent adhered well, and high-density shadows (indicating the broken guidewire) were visible between the stent and blood vessel. We implanted a 3.0*38 rapamycin-eluting stent in the distal part of the RCA. Dilatation pressure was $14 \mathrm{ATM}^{* 1} 10 \mathrm{~s}$. The patient had no chest tightness or shortness of breath (Fig. 6).

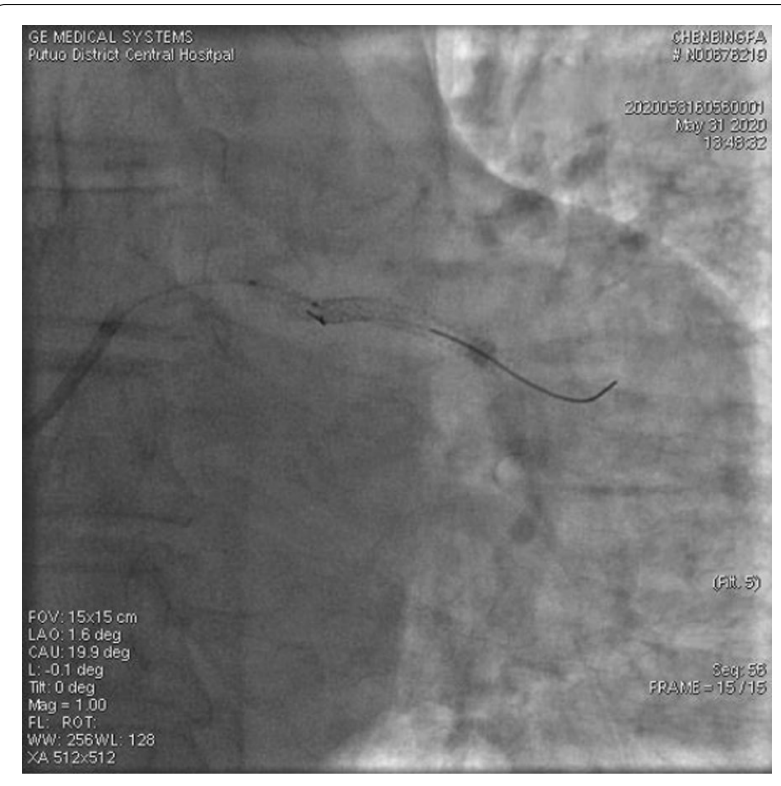

Fig. 4 placement of the second stent

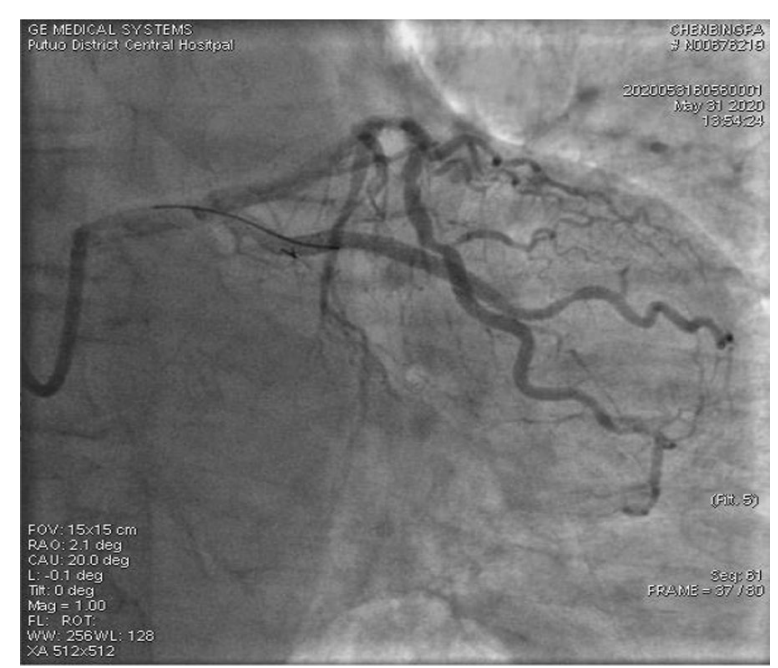

Fig. 5 Results of re-examination (postoperative)

\section{Discussion and conclusions}

The overall incidence of guidewire fracture ranges from 0.1 to $0.3 \%$ [1]. Therefore, it is very rare during percutaneous coronary interventions (PCIs). Fracture occurrence may be related to vascular anatomy. Excessive rotation, entry, and withdrawal of the guidewire may lead to the wire getting stuck in calcified complex coronary vessels [2]. Broken guidewires can cause serious complications, such as myocardial infarction, coronary artery perforation, cardiac tamponade, and thrombosis [3]. 

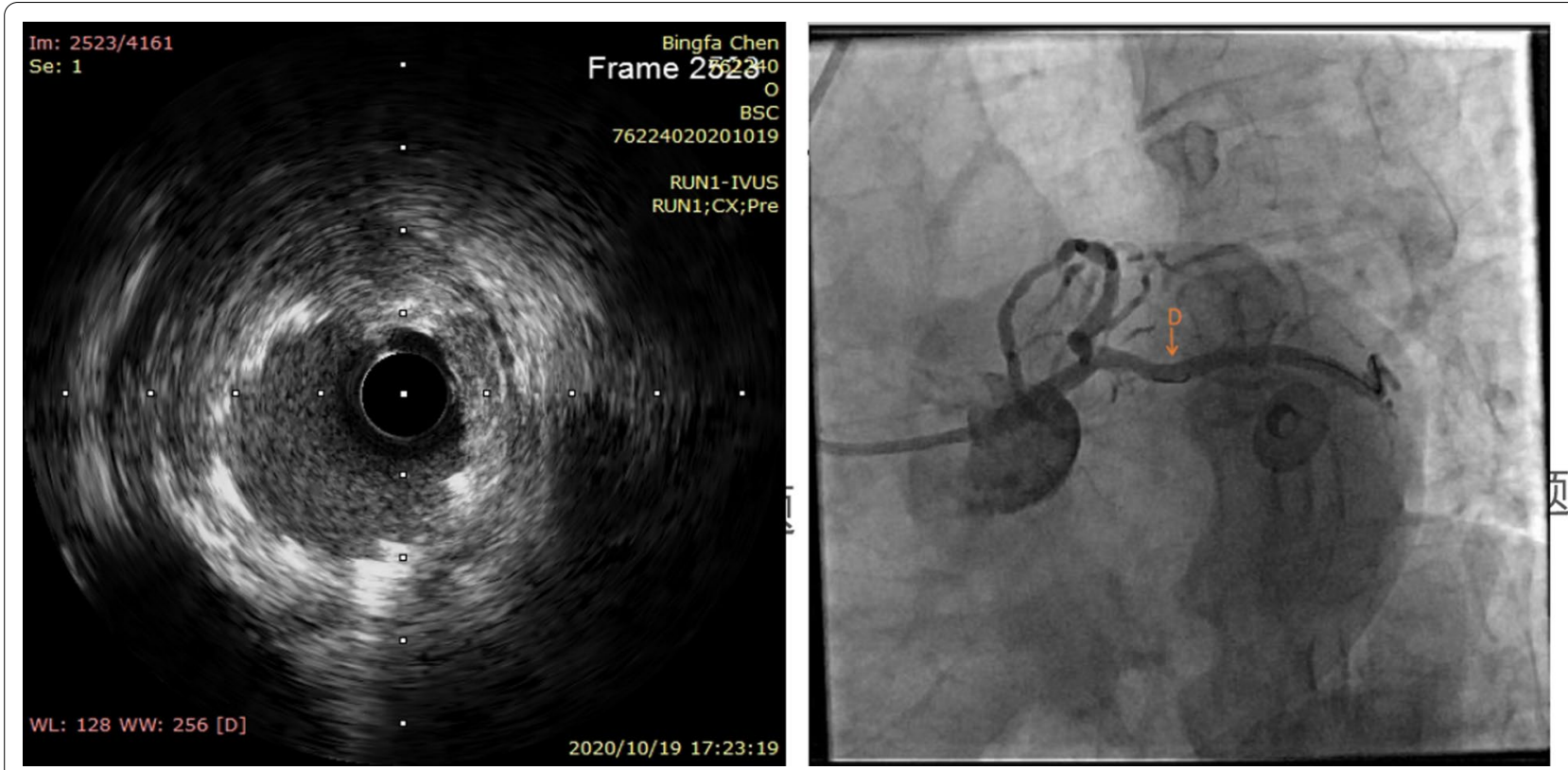

Fig. 6 Follow-up results of re-examination (6 months later) ivus

The common options for removing fractured guidewires include conservative, interventional and surgical treatments. In cases where a small part of the guidewire is broken and the patient is asymptomatic conservative treatments should be considered, and the guidewire can be left in the original position. In addition, these patients should take dual antiplatelet therapy with a follow-up period of a half year. Some experts consider that the long-term prognosis of patients with fractured guidewires in the coronary artery is good [4]. There is no special treatment for this condition. Interventional treatment includes stent placement and the use of multiple circumvoluted guidewires. Stent placemen is a common treatment for broken guidewires. Before using this method, the length of the stent must be clear. The stent can completely cover the broken guidewire. When the broken guidewire enters the aorta or a location that the stent cannot reach, the stent could cause thrombosis and aggravate the condition [5]. When the guidewire is broken in small or medium blood vessels, multiple circumvoluted guidewires can be used to move the broken guidewire back into the catheter [6]. If the broken guide wire cannot be removed by a traditional interventional method, there are various coronary snares, such as the EN intravascular net catcher, that can be used. It is composed of three cable metal rings and can firmly grasp and safely remove the broken guidewire. The platinum wire wrapped around each ring can enhance the angiographic effect [7]. If the patient worsens and develops hemodynamic instability, surgical treatment should be considered to completely remove the guidewire. Revascularization is then performed through coronary artery bypass grafting. However, surgical treatment has a high risk of bleeding and a long recovery time [8].

In this case, the three coronary vessels had severe stenosis. First, the stent and guidewire were successfully passed through the coronary artery. When we advanced and withdrew the guidewire, the front point of the guidewire caught on the stent. As a result, the coil of the guidewire was excessively straightened and it broke. In this case, the broken section of the guidewire was not in the coronary artery, so the problem could not be simply solved by stent coverage. The broken section of the guidewire was $40 \mathrm{~mm}$ away from the ostium. If covered by a stent, a $40 \mathrm{~mm}$ guidewire section could permanently remain in the aorta. Moreover, the crossmain stent would inevitably affect the opening of the LAD. This could make interventional treatment difficult in the future. When the snare pulls on the guidewire, this may further increase the deformation of the original stent due to traction and increase the risk of thrombosis. Therefore, we used rotational atherectomy in this case. The guidewire outside the LCX was removed while the guidewire in the LCX was covered by a stent. The results of follow-up suggest that this method is safe and feasible.

The common complications of rotational atherectomy include coronary artery spasm, coronary artery dissection, rotational head incarceration, the slow-flow/ no-reflow phenomenon and perforation [9]. We should 
have higher requirements for rotational atherectomy. The operators adopt a smaller rotational head and control the rotational atherectomy time. We gently push the rotary grinding head during operation to avoid a sudden drop in rotational speed and vibration. In addition, we pay attention to the patient's heart rate, blood pressure and ST-segment changes So we can reduce the complications and make the operation safer and more effective.

In short, guidewire rupture is a serious complication during percutaneous coronary interventions. Although it is very rare, it should be well recognized. In particular, patients with twisting blood vessels should be given more attention for this complication. The coronary artery characteristics and clinical conditions should be taken into consideration to select the best personalized treatment plan. Taking these factors into consideration can reduce the risk of bleeding and death, improving the survival rate of patients. At the same time, we should have higher requirements for the quality of the guidewires and operation technique.

\section{Abbreviations}

PCI: Percutaneous coronary intervention; LCX: Left circumflex; LAD: Left anterior descending artery.

\section{Acknowledgements}

Not applicable.

\section{Authors' contributions}

Project administration: JG, ZL. Supervision: JG. Validation: JY. Writing —original draft: XW. Writing —review and editing: JG. All authors read and approved the final manuscript.

\section{Funding}

The Shanghai Key Medical Specialties Construction Project (ZK2019A11); Clinical Advantage Discipline of Health System of Putuo District in Shanghai (2019ysxk01).

\section{Availability of data and materials}

The datasets used and/or analysed during the current study are available from the corresponding author on reasonable request.

\section{Declarations}

Ethics approval and consent to participate

The experimental protocol was established, in accordance with the ethical guidelines of the Helsinki Declaration, and was approved by the Ethics Committee of Putuo District Center Hospital, Shanghai. Written informed consent was obtained from the patient.

\section{Consent for publication}

Written informed consent was obtained from the patient for publication.

\section{Competing interests}

The authors declare that they have no competing interests.

Received: 29 July 2021 Accepted: 6 November 2021

Published online: 27 November 2021

\section{References}

1. Hartzler GO, Rutherford BD, McConahay DR. Retained percutaneous transluminal coronary angioplasty equipment components and their management. Am J Cardiol. 1987;60(16):1260-4.

2. Stathopoulos I, Panagopoulos G, Kossidas K, Jimenez M, Garratt K. Guidewire-induced coronary artery perforation and tamponade during PCl: in-hospital outcomes and impact on long-term survival. J Invasive Cardiol. 2014;26(8):371-6.

3. Kim TJ, Kim JK, Park BM, et al. Fatal subacute stent thrombosis induced by guidewire fracture with retained filaments in the coronary artery. Korean Circ J. 2013:43(11):761-5.

4. Baumann S, Rupp D, Becher T, et al. Retrieval of a fractured angioplasty guidewire after percutaneous retrograde revascularization of coronary chronic total occlusion. Coron Artery Dis. 2018:29(1):81-2.

5. Danek BA, Karatasakis A, Brilakis ES. Consequences and treatment of guidewire entrapment and fracture during percutaneous coronary intervention. Cardiovasc Revasc Med. 2016;17(2):129-33.

6. Datta G. Broken guidewire - a tale of three cases. Indian Heart J. 2015;67(Suppl 3):S49-52.

7. Senior J, Guillamo MR, Ghattas A, Tapp L. Dislodged coronary artery stent retrieved with an endovascular snare. Tex Heart Inst J. 2020;47(3):213-5.

8. Idhrees AM, Radhakrishnan BK, Panicker VT, Pillai V, Karunakaran J. Entrapment of guidewire in left anterior descending artery: surgical management. Asian Cardiovasc Thorac Ann. 2017:25(6):457-8.

9. Tomey MI, Kini AS, Sharma SK. Current status of rotational atherectomy. JACC Cardiovasc Interv. 2014;7(4):345-53.

\section{Publisher's Note}

Springer Nature remains neutral with regard to jurisdictional claims in published maps and institutional affiliations.
Ready to submit your research? Choose BMC and benefit from:
- fast, convenient online submission
- thorough peer review by experienced researchers in your field
- rapid publication on acceptance
- support for research data, including large and complex data types
- gold Open Access which fosters wider collaboration and increased citations
- maximum visibility for your research: over 100M website views per year
At BMC, research is always in progress.
Learn more biomedcentral.com/submissions 